Revista Bioética

\title{
ATUALIZAÇÃO
}

\section{Potência spinoziana: resistência ao controle sobre o modo de morrer}

Fernanda Rangel Ramos ${ }^{1}$, Túlio Batista Franco ${ }^{1}$

1. Programa de Pós-Graduação em Bioética, Ética Aplicada e Saúde Coletiva, Departamento de Planejamento em Saúde, Universidade Federal Fluminense, Niterói/RJ, Brasil.

\section{Resumo}

Este ensaio discute a tomada de decisão no fim da vida considerando o pensamento de Foucault e Spinoza. São tomados como referência dois pressupostos. O primeiro é o reconhecimento de tecnologia de gestão da vida que busca exercer poder sobre os corpos (biopoder) por meio de sistema disciplinar que prescreve modos de viver (biopolítica). O segundo pressuposto considera o conceito de corpo e a teoria dos afetos de Spinoza. Pôde-se concluir que, apesar dos obstáculos à tomada de decisão autônoma por parte dos pacientes, os indivíduos têm potência absoluta que lhes dá protagonismo. Seus pequenos gestos, no entanto, muitas vezes são invisíveis ao olhar dos profissionais de saúde.

Palavras-chave: Bioética. Tomada de decisões. Assistência terminal. Autonomia pessoal.

\section{Resumen}

Potencia spinoziana: resistencia al control sobre el modo de morir

Este ensayo analiza la toma de decisiones al final de la vida considerando el pensamiento de Foucault y de Spinoza. Se toman como referencia dos supuestos. El primero es el reconocimiento de la tecnología de gestión de la vida que busca ejercer poder sobre los cuerpos (biopoder) a través de un sistema disciplinario que prescribe formas de vida (biopolítica). El segundo supuesto considera el concepto de cuerpo de Spinoza y la teoría de los afectos. Se pudo concluir que, a pesar de los obstáculos para la toma de decisiones autónoma por parte de los pacientes, los individuos tienen un poder absoluto que les otorga protagonismo. Sin embargo, sus pequeños gestos suelen ser invisibles para los profesionales de la salud.

Palabras clave: Bioética. Toma de decisiones. Cuidado terminal. Autonomía personal.

\begin{abstract}
Spinozian power: resistance to control over death

This study discuss the issue of end-of-life decision-making, considering Foucault's ideas of a technology for managing life that exerts power over bodies (biopower) by a disciplinary system, and politics that prescribes ways of living (biopolitics), and Spinoza's concept of the body and affects (affectus). We conclude that, despite the numerous obstacles to autonomous decision-making by patients, individuals have an absolute power that favors their protagonism. However, their small gestures are often invisible to health professionals.

Keywords: Bioethics. Decision making. Terminal care. Personal autonomy.
\end{abstract}

Declaram não haver conflito de interesse. 
Este ensaio pretende discutir a tomada de decisão ao fim da vida partindo de dois pressupostos. O primeiro é o reconhecimento de que há tecnologia de gestão da vida - técnicas de governo das populações que buscam exercer biopoder sobre os corpos por meio de sistemas disciplinares e de política que prescreve modos de viver, a biopolítica. Esse debate auxilia a reflexão acerca de como a terminalidade se associa à questão do governo e do poder ${ }^{1}$.

O segundo pressuposto parte de Spinoza ${ }^{2}$, segundo o qual o humano não segue inerte a ordem da natureza, mas tem potência absoluta sobre suas ações, sendo determinado por si próprio. Desse modo, no contexto da saúde, a decisão, frequentemente atribuída ao profissional, especialmente ao médico, tem de ser tomada pelos pacientes, que devem protagonizar o final de sua vida.

Esse ativismo sobre si mesmo não é reconhecido por profissionais da saúde que se centram apenas nas possibilidades científicas de intervenção sobre os corpos. Porém, o que se observa é intensa atividade de indivíduos aos quais já não se atribui vida plena, mas que em muitos casos preservam a capacidade de escolher seu fim. Todo corpo tem potência e é capaz de afetar e de ser afetado. A atividade do corpo, sua vitalidade, é medida por esta capacidade de afetar, aumentando ou reduzindo sua possibilidade de agir ${ }^{3}$.

Entende-se que esses dois pressupostos dialogam entre si, articulando a dimensão societária e de governo dos vivos com a micropolítica dos afetos, em que há alta potência de ação e resistência aos mecanismos de controle. Tomando por referência a ideia de que vida e morte estão relacionadas ao contexto social, ambiental e aos modos de vida de determinado tempo, importa perceber que a urbanização acelerada a partir da década de 1970, que resultou na migração da população do campo para as cidades, transformou o perfil demográfico do Brasil ${ }^{4}$.

Como consequência dos avanços técnico-científicos que acompanharam esse processo, houve queda da taxa de natalidade e aumento da expectativa de vida ao nascer ${ }^{4}$. O fenômeno da urbanização mudou ainda o perfil alimentar e de atividade física da população, aumentando a prevalência de doenças crônico-degenerativas. Esses fatores, associados às novas técnicas de manutenção e prolongamento da vida, dilataram o processo de morte, intensificando o padecimento do doente ${ }^{4,5}$.

Portanto, vem crescendo a preocupação com questões relacionadas ao fim da vida, incluindo o cuidado e a prevenção do sofrimento. Dentre essas questões está a comunicação a respeito do tratamento entre pacientes, familiares e profissionais de saúde. Considerar o tratamento a que a pessoa gostaria de ser submetida, incentivando a tomada de decisão compartilhada, é parte da boa prática clínica ${ }^{6}$.

Nas situações em que o profissional toma a decisão pelo paciente, não é só o prognóstico que influencia o julgamento, mas também valores e crenças pessoais. No entanto, nem sempre a opinião da equipe médica coincide com valores do paciente e de seus familiares. Sprung e colaboradores ${ }^{7}$ mostraram que, enquanto profissionais valorizam mais a "qualidade de vida", pessoas atendidas atribuem mais valor à vida em si, a despeito de seu bem-estar ${ }^{6-9}$.

Para evitar decisões equivocadas, Schwarz ${ }^{8}$ sugere que a tomada de decisão seja compartilhada, tanto com membros da equipe como com pacientes e seus familiares. Para o autor, a discussão e a deliberação em conjunto, além de contemplar os melhores interesses do paciente, favorecem a reflexão moral. Na prática, no entanto, não há direitos iguais na comunicação, uma vez que as partes têm acesso desigual ao poder de decidir ${ }^{10}$.

Para Rego e Palácios, em geral a morte é determinada pelo médico ${ }^{11}$. Entretanto, a questão de quando e como morrer não deveria ser encarada como direito do profissional, mas sim do titular da vida. Antes de ser médico, o problema diz respeito à autonomia das pessoas e ao direito à morte digna ${ }^{12}$. Considerando a importância e a complexidade do tema, este ensaio discute como ocorre o processo de tomada de decisão no fim da vida, dados os diversos mecanismos envolvidos.

\section{Dispositivos na terminalidade da vida}

Hipócrates, o "pai da medicina", defendeu elevados padrões morais para a profissão, definindo como objetivos para a prática médica aliviar o sofrimento do doente, diminuir a agressividade da doença e não expor o enfermo a tratamentos quando não há mais benefício possível, segundo Bitencourt e colaboradores ${ }^{13}$. Os autores afirmam ainda que, para o filósofo, a medicina não devia tratar aqueles que foram vencidos pela doença, admitindo impotência perante casos em que não há perspectiva de cura.

A evolução da ciência, da tecnologia e dos medicamentos trouxe benefícios ao tratamento dos pacientes criticamente enfermos, mas também a possibilidade de postergar a morte por tempo 
indefinido. $\mathrm{O}$ uso indiscriminado de recursos artificias prolongou a vida, mas a qualquer custo, mantendo funções vitais sem o mínimo respeito à dignidade humana do paciente ${ }^{14}$.

Segundo Villas-Bôas ${ }^{15}$, pratica-se distanásia quando o tratamento não alcança mais seus objetivos e os recursos terapêuticos são utilizados para prolongar a vida de pacientes com doenças incuráveis, sem possibilidades reais de êxito e benefícios significativos ao prognóstico e à qualidade de vida. $O$ sofrimento então se torna maior que o benefício, e nesses casos é desumano persistir com o tratamento. Se acontece à revelia do enfermo, a distanásia não só elimina o conforto, mas ainda fere a dignidade humana ${ }^{9,15}$.

A dificuldade em lidar com a morte, sentida tanto por pacientes e familiares como por profissionais de saúde, tem favorecido essa prática. Apesar de não existir dever jurídico que imponha tal conduta, equipes continuam investindo no tratamento do paciente terminal por medo de constrangimento legal, buscando se defender de acusações de má prática ${ }^{16-18}$. Mas o fato de os recursos existirem não implica que devam ser utilizados em todos os pacientes, a todo momento e sob qualquer circunstância, pois nem tudo que é tecnicamente possível é eticamente correto ${ }^{15,19}$.

Até o século $\mathrm{XX}$, a morte era considerada processo natural, destino comum dos seres vivos. No período que precede a tecnificação da medicina, morria-se em casa, e o moribundo era em geral cercado por familiares, amigos e conhecidos e acompanhado por religioso encarregado de conduzir os rituais mortuários. Essa forma relativamente simples e tranquila de encarar o fim da vida foi sendo esquecida à medida que os avanços da medicina se faziam presentes. Diante de fármacos, exames, procedimentos clínicos e cirúrgicos cada vez mais eficazes, a morte passou a ser considerada algo pavoroso, uma transgressão à vida. Na segunda metade do século $X X$, ela se torna definitivamente inconveniente; vira tabu. A partir de então não se morre mais em casa, mas no hospital ${ }^{20}$.

Outros fatores que motivam a distanásia são a ideia equivocada de que ela é forma de cuidado e a referência ao modelo biologicista, que enfatiza a saúde como intervenção competente sobre o corpo depositário do processo mórbido. O fascínio pelos avanços tecnológicos da indústria de equipamentos - alimentado por estratégias de marketing, pela mídia e por microestruturas de intervenção no ambiente de trabalho - intensifica a percepção de que a morte é obstáculo que pode (e deve) ser superado pela ciência e pela medicina ${ }^{21}$. Isso se reflete na formação dos profissionais, que aprendem muito sobre tecnologia de ponta, sobre como salvar vidas, mas pouco sobre a morte. Os profissionais não são preparados para lidar com o fim da vida ${ }^{22}$.

Nesse contexto, a ortotanásia surge para contemplar o morrer bem, usando recursos de cuidado para pacientes com doenças sem cura, de modo a proporcionar condições para morte digna, serena, trabalhando especialmente a dimensão afetiva na hora de morrer. Ela é defendida sempre que não haja mais possibilidade de recuperação e a decisão sobre o tratamento possa ser tomada pelo enfermo de forma lúcida e responsável. A ortotanásia valoriza a autonomia do indivíduo, respeitando suas cren-

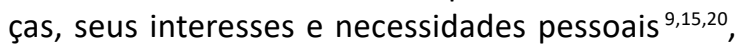
evitando que procedimentos sejam utilizados indiscriminadamente. Seu objetivo é prover conforto ao paciente. Essa abordagem não é considerada crime, pois compreende a indicação ou não de determinado tratamento, sem abreviar nem prolongar a vida do paciente, e está fundamentada nos princípios bioéticos ${ }^{15,23}$.

Ademais, a Organização Mundial da Saúde (OMS) recomenda cuidados paliativos em casos de doenças que ameaçam a vida. Conforme Oliveira, a OMS define esse tipo de assistência como abordagem que promove qualidade de vida de pacientes e seus familiares (...) por meio da prevenção e alívio do sofrimento. Requer a identificação precoce, avaliação e tratamento impecável da dor e outros problemas de natureza física, psicossocial e espiritual $^{24}$. O objetivo do cuidado paliativo não é curar ou controlar a doença, mas promover o conforto do paciente sem interferir na evolução da enfermidade. Sua finalidade é obter melhor qualidade de vida, controlando a dor e aliviando sintomas, de modo a garantir a dignidade da pessoa e humanizar o processo de morte ${ }^{15,25}$.

Já a eutanásia é entendida como antecipação da morte, por vontade do paciente, como alternativa humanitária para interromper sofrimento insuportável. O posicionamento contrário a esse ato tem como base o princípio da sacralidade, segundo o qual a vida é bem concedido por divindade, e portanto é sempre digna de ser vivida. Segundo essa concepção, apesar do sofrimento, a vida do paciente não pode ser interrompida, nem mesmo se essa for a vontade expressa da própria pessoa ${ }^{5,26}$.

Além disso, há o medo da morte, qualificada como mal, que leva à objeção primária contra a eutanásia ativa e voluntária do outro. Igualmente, do ponto de vista do profissional de saúde, em especial 
o médico, desde a formação a morte é tratada como erro, como adversário a ser combatido e vencido. Assim, a dialética vida-morte passa a estar sempre presente: ou o médico acerta ou o paciente morre ${ }^{26,27}$.

No entanto, há vozes a favor da eutanásia que, baseadas no princípio da autonomia, defendem a liberdade de escolha do indivíduo, permitindo que este defina o desfecho de sua vida, mesmo que sua decisão seja acabar com o sofrimento por meio da própria morte ${ }^{26}$. A pessoa mais indicada para decidir sobre o fim de sua vida é ela própria. Parece coerente respeitar seu desejo de cessar sofrimento insuportável e indesejável ou, pelo contrário, de continuar padecendo, se essa for sua vontade ${ }^{12,26}$.

A decisão sobre o fim da vida é direito moral de cada indivíduo, e como tal deve ser respeitada pela sociedade e protegida pelo Estado de direito. Apesar de formado para salvar vidas, o médico deve reconhecer os valores do paciente, compreendendo que seu conhecimento técnico não deve se sobrepor à decisão do indivíduo sobre sua própria existência. Ademais, o princípio da autonomia coloca o paciente como única autoridade moral sobre seu corpo. A princípio, ninguém tem o direito de decidir por ele ou limitar sua decisão ${ }^{12,28}$.

Seres racionais fazem escolhas livres e, portanto, autônomas. O indivíduo, como unidade mínima da moral, escolhe para si aquilo que considera fundamental, assim como define como deseja viver e o que considera vida digna - e isso deve ser extrapolado para a morte. Assim, considera-se imoral impedir decisões sobre a terminalidade tomadas por indivíduos capazes de determinar seu próprio $\mathrm{fim}^{12}$. Atitudes paternalistas, muitas vezes baseadas no princípio da sacralidade, negam o que a pessoa escolhe para si.

Essa ingerência viola a autonomia, impondo condição de menoridade que nega a autoria do sujeito sobre a própria vida. Não se pode negar ao indivíduo, que fez escolhas sobre todos os aspectos fundamentais de sua existência, o direito de decidir sobre seu fim. O que deveria ser sagrado é o respeito à pessoa, à autonomia do paciente e à sua dignidade.

Desta forma, a questão-chave na assistência ao final da vida é a da decisão informada ${ }^{29}$. Os profissionais devem comunicar ao enfermo os dados de sua condição sem nenhum juízo de valor, sendo a decisão de inteira responsabilidade do paciente ou de seu representante. Vale ressaltar, no entanto, que não se trata de transferir a responsabilidade para o paciente, mas de fornecer as informações técnicas necessárias, certificando-se de que elas foram entendidas e respeitando a escolha consciente e autônoma.

\section{O poder do Estado e a tomada de decisão no fim da vida}

Do século XVII até a primeira metade do século $\mathrm{XVIII}$, as técnicas de poder eram essencialmente centradas no corpo, por meio da tecnologia disciplinar do trabalho, individualizante. Na segunda metade do século XVIII, surge nova tecnologia de poder, massificante, que visava não mais atingir o homem-corpo, mas o homem-espécie. Como descreve Foucault ${ }^{3}$, passa-se da "anátomo-política" para a "biopolítica".

Nesse momento surgem os objetos de saber, trazendo informações sobre natalidade, mortalidade e longevidade. A medição estatística desses fenômenos gera as primeiras demografias, que evidenciam os primeiros alvos da biopolítica, definindo seu campo de intervenção. Essa nova política tem mecanismos diferentes, regulamentadores em vez de disciplinares, mas que controlam o comportamento da mesma forma, visando manter o equilíbrio global ${ }^{1}$.

O poder de fazer morrer ou deixar viver, soberano, dá lugar ao biopoder, que controla acidentes, adversidades e eventualidades para proporcionar mais vida e assim manter a força de trabalho. Sendo cada vez mais o direito de fazer viver, esse poder desqualifica a morte e suas cerimônias, tornando-as vergonhosas ${ }^{3}$. Ele assume novo campo, que consiste não só em organizar a vida e fazer viver, mas fazer viver mesmo além da "morte".

O biopoder pode fazer a pessoa viver mesmo quando, biologicamente, deveria estar morrendo, tornando possível a prática da distanásia, que é a interseção entre a soberania sobre a morte e a regulamentação da vida ${ }^{3}$. Do mesmo modo, o Estado detém o controle sobre quem deve viver ao proibir a prática da eutanásia àqueles que decidiram por isso autonomamente. Em suma, o biopoder passa a configurar a governamentalidade, transformando a vida em seu objeto.

\section{Relação médico-paciente e o poder saber}

Na relação médico-paciente, o profissional supostamente detém o conhecimento científico, e portanto está sempre em posição hierarquicamente superior na tomada de decisão sobre saúde, modos de vida, projetos terapêuticos e momento da morte. Assim, o médico teria o poder de definir o que é 
certo, quais hábitos devem ser seguidos e quais são as melhores condutas. Esta situação, por si só, já submete o paciente a relação desigual e assimétrica ${ }^{1,3}$.

Esse posicionamento vem sendo construído desde os séculos XVII e XVIII, quando a medicina era classificatória, focada no quadro nosográfico. $O$ olhar superficial do médico analisava e categorizava a doença. No final do século XVIII, esse tipo de prática deu lugar à medicina clínica, devido à mutação na ordem do conhecimento médico. Surgiram então novos "códigos do saber", fundados na percepção. Enquanto a medicina clássica catalogava as doenças na tentativa de ilustrar a teoria, a medicina clínica funda seu objeto na sensorialidade do saber ${ }^{30}$.

No século XIX nasce a "anatomoclínica", conforme nomenclatura de Foucault ${ }^{30}$, a partir da conjunção da prática clínica com a anatomia patológica. Novo domínio, o da anatomia, passa a ser explorado. A proposta é localizar a doença no órgão afetado e, desse modo, definir o corpo doente como âmbito da percepção médica. Junto com a medicina, como prática e ciência, foi reorganizado também o domínio hospitalar, que assumiu a função de espaço para prática médica e construção do saber. A medicina anatomoclínica entrega o indivíduo inerte ao conhecimento, como objeto a ser desvendado pela autópsia.

A assistência atual tem como foco a doença e o tratamento prescritivo, simplificando e enrijecendo o trabalho médico. As tecnologias mais relacionais, que consideravam o indivíduo integralmente, resultante de processo saúde-doença e influenciado por fatores socioambientais, foram perdendo espaço para o consumo exagerado de tecnologias instrumentais ${ }^{31,32}$.

Merhy ${ }^{32}$ descreve a atuação do médico a partir de três valises. A primeira, vinculada às mãos, refere-se a equipamentos e instrumentos (tecnologias duras). A segunda, relacionada à cabeça, abrange saberes, conhecimentos sobre a clínica e epidemiologia (tecnologias leves-duras). A terceira se liga à relação trabalhador-usuário (tecnologias leves).

Certo arranjo dessas três valises permite produzir intervenção médica com ênfase nos procedimentos, focando apenas em possibilidades técnicas, sem atentar para as necessidades e planos do indivíduo, de modo a favorecer, por exemplo, a prática da distanásia. Outros arranjos, porém, podem gerar intervenção centrada no cuidado, mais atenta ao projeto de vida do paciente e mais favorável à tomada de decisão autônoma no fim da vida. A primeira abordagem, baseada no consumo de tecnologia e procedimentos, é estimulada pela lógica capitalista, que vislumbra na medicina produtivo campo de investimento ${ }^{32}$.

\section{Normalização da vida}

Fundamentando as definições sobre a vida e a morte do indivíduo, há relações concretas de poder e saber. No campo do cuidado em saúde, não se exerce o poder pela força, pelos aparelhos do Estado, mas por saberes específicos e tecnologias de controle e ordenação que, sob o pretexto de desenvolver o bem-estar, sujeitam os indivíduos a dispositivos estratégicos de gestão da vida. O Estado não é o único detentor do poder; há diversos micropoderes articulados a ele atuando na sociedade ${ }^{33}$.

As disciplinas agem por meio da coerção ininterrupta, esquadrinhando o espaço, o tempo e o movimento, ordenando a multiplicidade humana para facilitar o exercício do poder. Elas aperfeiçoam o corpo do ponto de vista econômico, mas minimizam sua força política. Por meio delas, as relações de poder podem funcionar de forma mais discreta, transformando multidões confusas e politicamente perigosas em multiplicidades ordenadas e dóceis ${ }^{3,33}$.

Assim como a vigilância, a normalização se tornou um dos grandes instrumentos de poder ao final da época da medicina clássica. Ela institui parâmetros de normalidade, categorizando e distribuindo classes $^{3,33}$. A norma surge por meio da disciplina, estabelecendo o comum como princípio de coerção já no ensino, mediante educação padronizada. E o mesmo ocorre no espaço hospitalar ${ }^{3,33}$. Uma das estratégias de normalização na medicina é o exame, que combina hierarquia e sanção. O olhar do exame normaliza: qualifica, classifica e pune, executa a cerimônia do poder e estabelece a verdade. Trata-se de técnica tanto do poder como do saber - não por acaso, uma das mais utilizadas em hospitais ${ }^{3,33}$.

A partir do século XVIII, com o surgimento da biologia como ciência da vida, os mecanismos de poder se voltam ao corpo, agindo sobre os indivíduos por meio da norma, do saber, da disciplina e das regulamentações ${ }^{3}$. Com as transformações no direito político, o poder, antes exercido pela prerrogativa de deixar viver ou fazer morrer, passa a ter como propósito garantir, sustentar, reforçar, multiplicar e ordenar a vida. As tecnologias políticas se proliferam, investindo sobre o corpo, a saúde, a alimentação, os hábitos e todos os aspectos da existência ${ }^{3,33}$.

No século XIX, a partir do controle, da vigilância e do exame, conforma-se o saber sobre o ser 
humano que define o normal e o anormal. Saberes e práticas passam a ordenar as multiplicidades humanas, homogeneizando as diferenças por meio da disciplina e da normalização. Processos de inclusão e exclusão social são alimentados de acordo com o binômio normal-anormal ${ }^{33}$.

"Normal" passa a designar, além do protótipo escolar, estado de saúde orgânica. O termo se estabelece em vários campos como princípio de coerção. No hospital, isso se dá por meio de corpo médico capaz de fazer funcionar normas gerais, dentre elas a da vida. O "normal" é viver, ter saúde, e tudo que seja diferente disso é considerado anormal e inaceitável $^{33}$. A medicina considera a doença e a morte como desvios. Seu objetivo é trazer o organismo de volta ao estado saudável, e tudo é feito para que o indivíduo viva e recupere a saúde. $O$ paciente que não quer mais viver foge à norma estabelecida cientificamente ${ }^{33}$.

Modos de resistir à normalização são as técnicas de governo e cuidado de si, a arte de não ser governado ${ }^{33}$. A partir do final do século $X X$, ocorre maior conscientização e consequente valorização da luta contra a sujeição dos indivíduos. Foucault ${ }^{34} \mathrm{faz}$ pensar em formas de poder alternativas aos saberes e poderes modernos, como o das ciências biomédicas, focando a relação do indivíduo consigo mesmo.

Derivada de processos econômicos e sociais, a sujeição se baseia em saberes e poderes exercidos pelo Estado, que determinam formas de subjetividade. As análises de Foucault buscam modos de resistir por meio da elaboração de subjetividade própria, afastada do poder normalizador das leis e das ciências. Para o autor, não há outra forma de resistir ao poder político senão partindo da relação consigo, centralizada na constituição de si como sujeito moral ativo ${ }^{33}$. A preocupação com o cuidado de si tem crescido, mudando conceitos, construindo estratégias críticas e problematizando a relação do sujeito com a "verdade" ${ }^{33}$.

\section{Medicalização da vida e da morte}

A medicalização da vida e da morte vem crescendo nos últimos 50 anos. $\mathrm{O}$ alcance deste processo e seus efeitos preocupa pesquisadores da saúde e das ciências humanas ${ }^{35}$. Foucault ${ }^{34}$ colabora com o debate, mas a medicalização que descreve corresponde a processo histórico que vai do final do século XVII ao início do XIX, com o surgimento da biopolítica e o controle do corpo por meio da pedagogização da sexualidade das crianças, histerização das mulheres e psiquiatrização das perversões.

Para Foucault ${ }^{3}$, é impossível que essas experiências com o corpo humano não passem, de alguma forma, pela medicina, edificada como instituição do controle social ${ }^{36}$. Isso aconteceria por meio da imposição, independentemente do estado de saúde do sujeito, de políticas sistemáticas de rastreamento da população em busca de doenças, pela compulsoriedade de exame psiquiátrico em acusados de delitos e pela ausência de experiências corporais não médicas ${ }^{3,36}$.

A partir do século $X X$, as ciências não médicas perdem cada vez mais espaço para as ciências médicas, e a medicalização já não encontra limites para definir o que é normal e anormal. A doença mental, produzida socialmente, é então considerada desviante. Todo tipo de problema é definido como transtorno médico ${ }^{3,36}$. A medicalização consiste, portanto, na expansão da medicina para além do seu campo tradicional, criando novas doenças ao considerar qualquer transtorno antes não tratável como passível de tratamento. Como consequência, aumenta o consumo de medicamentos e métodos diagnósticos, alimentando a indústria farmacêutica e de biotecnologia ${ }^{35,37}$.

Corrêa ${ }^{38}$ fala em "medicalização social", definindo-a como redescrição de eventos fisiológicos e comportamentos sociais que tem efeito sobre o consumo médico e a produção de conhecimento. A autora entende a medicalização como forma pela qual o avanço tecnológico influencia a medicina, criando procedimentos e produtos e estabelecendo normas de conduta. $O$ processo tem possibilidade de ampliação ilimitada, já que qualquer condição é passível de ser reescrita em termos médicos.

A medicalização rotula, descreve doenças e autoriza experiências com o corpo em nome do "avanço" e da busca pela "cura", culminando na privação da autonomia dos indivíduos, que se tornam alvos passivos dos dispositivos de controle médico. Com isso, a medicina passa a regular o comportamento social do indivíduo, dificultando a tomada de decisões relativas ao próprio corpo e destino. Membros de um grupo autoritário ditam normas de como outros grupos devem se comportar, e os pacientes ficam sem oportunidade para questionar decisões de especialistas. Desse modo, a medicalização age como imperialismo médico ${ }^{36,38}$.

Esse processo só foi possível devido ao desenvolvimento tecnológico, que, apesar dos muitos benefícios, trouxe efeitos indesejáveis, como a mercantilização da saúde. A medicalização da vida e da 
morte é prática que foge aos princípios morais e éticos da medicina ${ }^{35}$. No entanto, vale ressaltar que isso não se deve à tecnologia em si, mas a seu mau uso. A noção de que a técnica pode proporcionar vida cada vez melhor dá a ideia de que o progresso seria ilimitado. 0 corpo, porém, tem limites ${ }^{35}$.

Com a medicalização, a medicina participa cada vez mais do processo de morrer. A morte deixa de ocorrer em casa, com os familiares, e passa a ser institucionalizada. A medicina é vista como milagrosa, como saber que tudo cura; mas a morte é inevitável, e não se resume a questão médica ${ }^{35,36}$.

\section{Protagonismo do paciente}

O termo "paciente" reforça a relação assimétrica e, apesar de ser utilizado rotineiramente, deve ser problematizado, uma vez que o indivíduo, mesmo se portador de doença incurável, é ativo. Todo ser humano tem biografia e o direito a ser informado sobre sua doença e opções de terapia disponíveis. É preciso respeitar sua autonomia na escolha de seu tratamento ${ }^{23}$. Partindo da ideia de potência ${ }^{2}$, deve haver protagonismo do paciente na tomada de decisões.

Segundo Spinoza ${ }^{2}$, todo corpo tem potência, e ser livre é exercitá-la ao máximo. Por conseguinte, estaria sujeito à servidão o ser que tem seus afetos regulados e refreados pela impotência. O filósofo define os afetos como ideias confusas, paixões primárias da alma, como alegria e tristeza. Essas sensações podem aumentar ou reduzir a potência de agir, que é afetada pelas relações, e o próprio indivíduo é quem determina os remédios contra os afetos ${ }^{2}$.

Os poderes estabelecidos precisam de nossa tristeza, de nossa potência negativa, para reduzir a potência de agir e nos fazer escravos. Assim, controlar os afetos seria estratégia para se desvencilhar desses poderes. Ter ideia clara e distinta dessas paixões é distingui-las pela razão. Quanto mais um afeto estiver sob o poder do indivíduo, quanto mais for conhecido, menos a mente padecerá por sua causa ${ }^{2}$.

Franco e Galavote ${ }^{39}$ analisam caso que mostra a insuficiência da clínica biologicista como concebida pelo poder hegemônico, com base no modelo Flexner ${ }^{40}$. O exemplo ilustra perfeitamente o pressuposto de que afetos operam a produção de si e do outro e configuram modos de vida pelos quais um corpo pede reconhecimento.

O caso trata de indivíduo que sofreu acidente e foi informado de que seu prognóstico era reservado e lhe restavam poucos meses de vida. Após a alta, além de seu estado de saúde não evoluir, a despeito de acompanhamento técnico domiciliar, o paciente começou a definhar. No entanto, após mudança do responsável pelo caso, sua recuperação foi notável.

A hipótese para essa melhora diz respeito a aspectos subjetivos. Com a troca do profissional, a potência de agir do indivíduo, até então inerte, pode ter sido ativada ${ }^{39}$. A partir do prognóstico, os médicos tomaram pelo paciente a decisão de desistir. Quando retoma as rédeas de sua vida, que volta a ter sentido, o indivíduo torna-se ser altamente desejante, potente. Nesse processo, a relação médico-paciente mostrou-se fundamental.

A compreensão puramente biológica do corpo como estrutura ou sistema em funcionamento é insuficiente para intervenção eficaz, impedindo o atendimento às necessidades do indivíduo. Como contraponto, surge o conceito de corpo sem órgãos, tornando possíveis outras práticas de cuidado ao operar pelos afetos ${ }^{39}$.

Com o conhecimento do corpo anatomoclínico surge o critério de verdade da clínica do olhar, caracterizada pelo "olho-retina", que enxerga o plano visível, mas não a subjetividade, como se o corpo se resumisse à sua estrutura ${ }^{39}$. Tal clínica desconsidera o corpo sem órgãos, centrado na dimensão relacional, capaz de recuperar sua potência de agir no mundo - o corpo sensível, inapreensível ao "olho-retina" 39.

Quando a força vital do paciente não é estimulada, é difícil ativar sua energia desejante, sua potência para o cuidado de si. O indivíduo então torna-se mais propenso a deixar o poder de decisão nas mãos do outro, dos dotados do saber. No caso citado ${ }^{39}$, no primeiro momento o paciente foi visto pelo prisma do pensamento hegemônico, como corpo anatomofisiológico considerado morto na dimensão relacional. $\mathrm{O}$ indivíduo teve, portanto, um mau encontro, que produziu "paixões tristes" que reduziram sua força desejante e capacidade de agir no mundo.

No segundo momento, como relata o estudo, o afeto é mútuo. Cuidador e paciente têm sua potência de agir aumentada por "paixões alegres", e o cuidado toma outro rumo. Assim, Franco e Galavote ${ }^{39}$ sugerem que o olho-retina é insuficiente para cuidar de quem sofre e, como alternativa, propõem a conjunção do corpo sem órgãos com o corpo anatomoclínico. Para os autores, a clínica dos afetos, junto com a clínica do olhar, é ferramenta necessária para a assistência integral em saúde. 


\section{Considerações finais}

As questões relacionadas à terminalidade estão em evidência nas últimas décadas, especialmente devido às possibilidades geradas pelo desenvolvimento biotecnocientífico. No entanto, embora as novas tecnologias permitam diversos modos de morrer, a questão central nessa fase da vida é a tomada de decisão, que deve envolver pacientes e familiares devidamente informados sobre opções de tratamento, consequências e perspectivas.

Ao indivíduo que viveu toda sua vida com base em suas escolhas deve-se permitir também escolher seu fim. Apesar dos muitos fatores que dificultam a tomada de decisão, prevalece o protagonismo do paciente. O profissional deve ser sensível a pequenos gestos que podem indicar decisões, como a adesão ou não ao tratamento. Esses sinais são a própria opção terapêutica do paciente, que está tentando tomar o controle de seu corpo.

Na micropolítica dos cuidados, o paciente muitas vezes toma decisões invisíveis ao olhar dos profissionais de saúde, agenciados pela biomedicina. A decisão do indivíduo está presente, apenas precisa ser reconhecida. Assim, mesmo sem cura, há possibilidades terapêuticas que surgem do próprio paciente. Seja a decisão de decretar um "basta" ou de ir até o fim, o que ele decide, o que faz consigo mesmo nesse final de vida, faz parte do "cuidar de si".

\section{Referências}

1. Foucault M. Do governo dos vivos. São Paulo: CCS; 2010.

2. Spinoza B. Ética. Belo Horizonte: Autêntica; 2014.

3. Foucault M. Em defesa da sociedade. 2a ed. São Paulo: WMF Martins Fontes; 2012.

4. Vaz DS, Remoaldo PCA. A geografia da saúde brasileira e portuguesa: algumas considerações conceptuais. Geousp Espaço Tempo [Internet]. 2011 [acesso 27 jul 2020];15(3):173-92. DOI: 10.11606/issn.2179-0892.geousp.2011.74242

5. Rego S, Palácios M, Siqueira-Batista R. Bioética para profissionais da saúde. Rio de Janeiro: Editora Fiocruz; 2009.

6. Silvester W, Detering K. Advance directives, perioperative care and end-of-life planning. Best Pract Res Clin Anaesthesiol [Internet]. 2011 [acesso 21 jan 2016];25(3):451-60. DOI: 10.1016/j.bpa.2011.07.005

7. Sprung $\mathrm{CL}$, Carmel S, Sjokvist P, Baras M, Cohen SL, Maia P et al. Attitudes of European physicians, nurses, patients, and families regarding end-of-life decisions: the Ethicatt study. Intensive Care Med [Internet]. 2007 [acesso 10 jun 2019];33:104-10. DOI: 10.1007/s00134-006-0405-1

8. Schwarz JK. Responding to persistent requests for assistance in dying: a phenomenological inquiry. Int J Palliat Nurs [Internet]. 2004 [acesso 10 jun 2019];10(5):225-35. DOI: 10.12968/ijpn.2004.10.5.13071

9. Menezes MB, Selli L, Alves JS. Distanásia: percepção dos profissionais de enfermagem. Rev Latinoam Enferm [Internet]. 2009 [acesso 21 jan 2016];17(4). DOI: 10.1590/S0104-11692009000400002

10. Minetti A. Working together: an interdisciplinary approach to dying patients in palliative care unit. J Med Ethics [Internet]. 2011 [acesso 10 jun 2019];37:715-8. DOI: 10.1136/jme.2010.040980

11. Rego S, Palácios M. Cuidado médico e o fim de vida. In: Lopes D Jr, lacomini V, coordenadores. Bioética e biodireito: fim da vida. Curitiba: Juruá; 2015. p. 89-109. p. 102.

12. Dias MC. A decisão sobre o fim da vida: um direito fundamental. In: Lopes D Jr, lacomini V, coordenadores. Op. cit. p. 111-22.

13. Bitencourt AGV, Dantas MP, Neves FBCS, Almeida AM, Melo RMV, Albuquerque LC et al. Condutas de limitação terapêutica em pacientes internados em unidade de terapia intensiva. Rev Bras Ter Intensiva [Internet]. 2007 [acesso 10 jun 2019];19(2):137-43. DOI: 10.1590/S0103-507X2007000200001

14. Baruzzi ACA, Ikeoka DT. Terminalidade e cuidados paliativos em terapia intensiva. Rev Assoc Méd Bras [Internet]. 2013 [acesso 10 jun 2019];59(6):528-30. DOI: 10.1016/j.ramb.2013.06.018

15. Villas-Bôas ME. A ortotanásia e o direito penal brasileiro. Rev. Bioética [Internet]. 2008 [acesso 10 jun 2019];16(1):61-83. Disponivel: https://bit.ly/39xfMM8

16. Roxin C. A apreciação jurídico-penal da eutanásia. Rev Bras Ciênc Crim. 2000;32:9-38.

17. Monteiro $F$. Ventilação mecânica e obstinação terapêutica ou distanásia, a dialéctica da alta tecnologia em medicina intensiva. Rev Port Pneumol [Internet]. 2006 [acesso 10 jun 2019];12(3):281-91. Disponível: https://bit.ly/2EoVau9

18. Terzi RGG. O doente terminal. In: Birolini $D$, Helito AS, organizadores. Análise crítica da prática médica. São Paulo: Campus; 2010. p. 164-77.

19. Vincent JL. Ethical principles in end-of-life decisions in different European countries. Swiss Med Wkly [Internet]. 2004 [acesso 10 jun 2019];134(5-6):65-8. Disponível: https://bit.ly/303oU8b

20. Ogando B, García C. Morir con propiedad en el siglo XXI. Rev Calid Asist [Internet]. 2007 [acesso 10 jun 2019];22(3):147-53. DOI: 10.1016/S1134-282X(07)71210-1

21. Merhy EE, Franco TB. Por uma composição técnica do trabalho em saúde centrado no campo relacional e nas tecnologias leves: apontando mudanças para os modelos tecno-assistenciais. Saúde Debate. 2003;27(65):316-23. 
22. Vane MF, Posso IP. Perception of physicians of intensive care units of the Clinicas Hospital complex about orthothanasia. Rev Dor [Internet]. 2011 [acesso 10 jun 2019];12(1):39-45. DOI: 10.1590/S1806-00132011000100009

23. Santana JCB, Santos AV, Silva BR, Oliveira DA, Caminha EM, Peres FS et al. Docentes de enfermagem e terminalidade em condições dignas. Rev. bioét. (Impr.) [Internet]. 2013 [acesso 10 jun 2019];21(2):298-307. DOI: 10.1590/S1983-80422013000200013

24. Oliveira RA, coordenador. Cuidado paliativo. São Paulo: Cremesp; 2008. p. 16.

25. Santana JCB, Rigueira ACM, Dutra BS. Distanásia: reflexões sobre até quando prolongar a vida em uma unidade de terapia intensiva na percepção dos enfermeiros. Bioethikos [Internet]. 2010 [acesso 10 jun 2019];4(4):402-11. Disponível: https://bit.ly/39uO8PQ

26. Siqueira-Batista R, Schramm FR. Eutanásia: pelas veredas da morte e da autonomia. Ciênc Saúde Coletiva [Internet]. 2004 [acesso 10 jun 2019];9(1):31-41. DOI: 10.1590/S1413-81232004000100004

27. Ramsey C. The right to die: beyond academia. Monash Bioeth Rev [Internet]. 2016 [acesso 10 jun 2019];34:70-87. DOI: 10.1007/s40592-016-0056-0

28. Gracia D. Bioética clínica. Santa Fé de Bogotá: El Buho; 1998.

29. White DB, Malvar G, Karr J, Lo B, Randall Curtis J. Expanding the paradigm of the physician's role in surrogate decision-making: an empirically derived framework. Crit Care Med [Internet]. 2010 [acesso 10 jun 2019];38(3):743-50. Disponível: https://bit.ly/3hF706t

30. Foucault M. O nascimento da clínica. Rio de Janeiro: Forense Universitária; 2008.

31. Merhy EE, Franco TB. Reestruturação produtiva e transição tecnológica na saúde [Internet]. 15 jan 2002 [acesso 27 jul 2020]. Disponível: https://bit.ly/3jG2WA5

32. Merhy EE. Um ensaio sobre o médico e suas valises tecnológicas: contribuições para compreender as reestruturações produtivas do setor saúde. Interface Comun Saúde Educ [Internet]. 2000 [acesso 10 jun 2019];4(6):109-16. DOI: 10.1590/S1414-32832000000100009

33. Portocarrero V. As ciências da vida: de Canguilhem a Foucault. Rio de Janeiro: Editora Fiocruz; 2009.

34. Foucault M. Segurança, território, população. São Paulo: WMF Martins Fontes; 2008.

35. Cernadas JMC. La creciente medicalización de la vida: ¿somos los médicos conscientes de los perjuicios que produce? Arch Argent Pediatr [Internet]. 2012 [acesso 10 jun 2019];110(6):459-61. DOI: 10.5546/aap.2012.459

36. Zorzanelli RT, Ortega F, Bezerra B Jr. Um panorama sobre as variações em torno do conceito de medicalização entre 1950-2010. Ciênc Saúde Coletiva [Internet]. 2014 [acesso 10 jun 2019];19(6):1859-68. DOI: 10.1590/1413-81232014196.03612013

37. Bury M. The medicalization of society: on the transformation of human conditions into treatable disorders. Sociol Health IIIn [Internet]. 2009 [acesso 10 jun 2019];31(1):147-8. DOI: 10.1111/j.1467-9566.2008.01145_1.x

38. Corrêa MV. Novas tecnologias reprodutivas: limites da biologia ou biologia sem limites? Rio de Janeiro: EdUERJ; 2001.

39. Franco TB, Galavote HS. Em busca da clínica dos afetos. In: Franco TB, Ramos VC, organizadores. Semiótica, afecção e cuidado em saúde. São Paulo: Hucitec; 2010. p. 176-99.

40. Pagliosa FL, Da Ros MA. O relatório Flexner: para o bem e para o mal. Rev Bras Educ Méd [Internet]. 2008 [acesso 10 jun 2019];32(4):492-9. DOI: 10.1590/S0100-55022008000400012

\section{Participação dos autores}

Fernanda Rangel Ramos fez a pesquisa bibliográfica, elaborou e redigiu o artigo. Túlio Batista Franco colaborou na revisão do texto e deu sugestões na finalização da escrita.

\section{Correspondência}

Fernanda Rangel Ramos - Universidade Federal Fluminense. Departamento de Planejamento em Saúde. Av. Marquês do Paraná, 303, anexo, 3o andar, Centro CEP 24033-900. Niterói/RJ, Brasil.

Fernanda Rangel Ramos - Doutora - fernandarangel@hucff.ufrj.br

(iD) 0000-0002-6802-7969

Túlio Batista Franco - Doutor - tuliofranco@gmail.com

(iD) $0000-0001-7372-5262$ 